Journal of Transport and Land Use 1:1 (Summer 2008) pp. 1-4

Available at http://jtlu.org

\title{
Introducing the Journal of Transport and Land Use
}

\author{
David Levinson \\ University of Minnesota \\ General Editor ${ }^{\mathrm{a}}$
}

Hong K. Lo

Hong Kong University of Science and Technology

Asia/Pacific Editor

\author{
Kevin J. Krizek \\ University of Colorado \\ Americas Editor $^{\mathrm{b}}$
}

\author{
Martin J. Dijst \\ Utrecht University \\ Europe/Africa Editor
}

Jessica Y. Guo

University of Wisconsin

Book Review Editor

The Journal of Transport and Land Use launches with this issue. Transport and land use are two sides of the same coin; one does not build transport facilities or operate transport systems but to connect activities that occur on places. Those activities (or land uses) could not exist but for the transport that enables people and goods to reach them.

Several journals touch on the interaction of transport and land use; however, they do so peripherally. The new venue provided by this journal puts both transport and land use front and center. We seek to be the leading outlet for research at the interdisciplinary intersection of these two domains, including work from the domains of engineering, planning, modeling, behavior, economics, geography, regional science, sociology, architecture and design, network science, and complex systems.

This intersection is not a union. Research about transport that fails to consider land use, or studies of land use that ignore transport are not appropriate for this journal; many other suitable outlets exist. The intersection of transport and land use covers many disciplines. As a result, manuscripts may consider small-scale (the level of the building and street) or large-scale (intercity transportation and cities) interactions; may value equity, efficiency, the environment, or the user experience; may take the perspective of individuals, firms, or governments; may be empirical or theoretical; and may employ quantitative or qualitative methods.

The field of transport has steadily been establishing itself as an interdisciplinary field. From the canal and railway engineers of centuries past and highway engineers of the twentieth century, the field has grown in complexity with the demands placed on it. Transport planning emerged in the early twentieth century, forecasting at midcentury, and rigorous operational analysis in the 1960s. Subsequent achievements in the development of econometric techniques to model and forecast mode shares (such as

\footnotetext{
adlevinson@umn.edu

${ }^{b}$ krizek@colorado.edu
}

Copyright 2008 David Levinson, Kevin J. Krizek, Martin Dijst, Hong K. Lo, and Jessica Y. Guo. Licensed under the Creative Commons Attribution - NonCommercial License 3.0. 
logit models) were noted with a Nobel Prize in Economics. We have witnessed similar developments on the land use side of the coin.

Peer-reviewed publications related to issues of transport and land use have shown continued growth; Figure 1 displays the onset of journals related to these two general fields. Transport journals were launched with abandon in the 1960s and early 1970s,

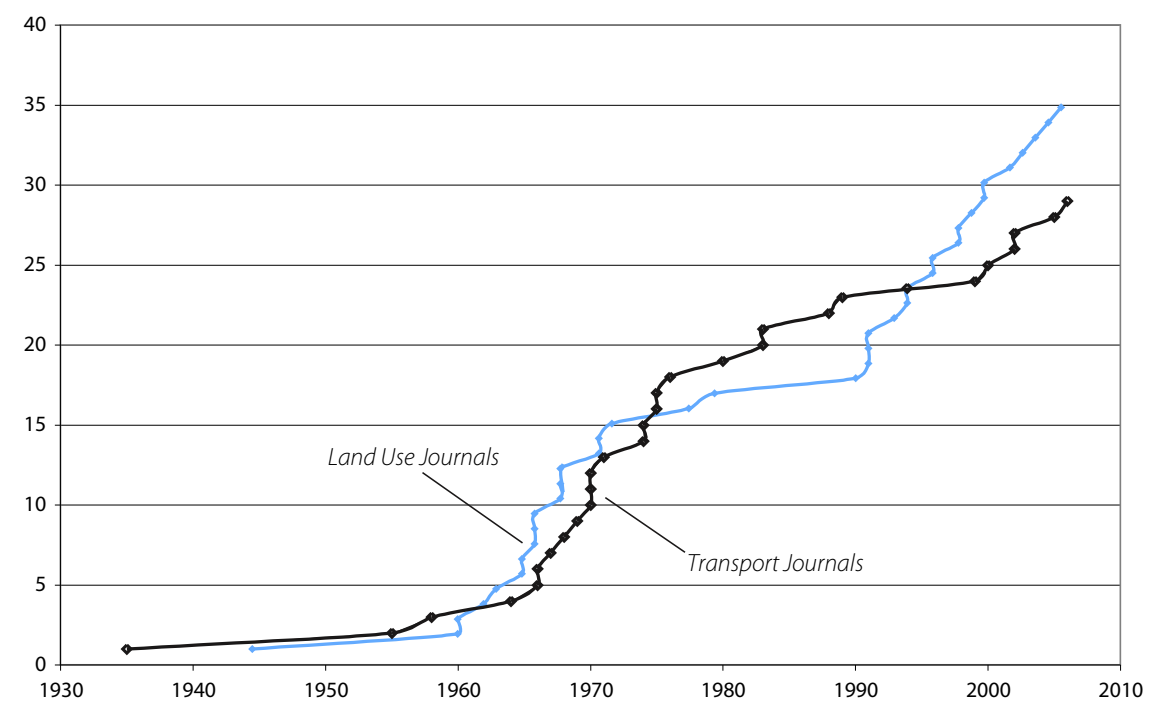

Figure 1: The rise of land use and transport journals

followed by a long lull from the late 1970s through the mid 1990s, during which only a few journals were launched. However, recent years have seen a new series of journals created. The trends among land use journals (including the fields of regional science, urban economics, and planning) reveal similar dynamics, if more modest and lagging a bit in recent additions. We conclude that a general increase in scientific output enabled by new information technologies - in particular computer-based production and web-enabled distribution - as well as a growing recognition of both planning and transportation as coherent disciplines has led to a boomlet in new journals in these fields. While many of the stalwart journals remain influential, new journals can rise quickly; the Journal of Economic Geography (launched 2000) and Transportmetrica (launched 2005) are examples of new entrants quickly rising to the top as measured by impact factor, a somewhat, though not entirely, arbitrary measure of a journal's influence on the outside world. 
JTLU is not just one more peer-reviewed journal throwing itself into the fray, though. JTLU embraces the open-content movement. Most academic publishing, especially in the "traditional model" that comprises most of the journals launched prior to the late 1990s, can be described as a "walled garden." Inside are the beauties of rich information, but to enter, the costs are steep. Such a model made sense in an age when journals were primarily distributed on paper, and publication costs were high. Today, however, most readers of nominally paper-based journals access the articles online, and the costs such as communications and server space are small enough as to be inconsequential for a single journal.

The main costs - those of writing, reviewing, and editing articles—have historically been gratis (at most, the participants earn social capital which perhaps can later be monetized), while copy-editing and layout do entail real costs and have historically been recovered by charging either readers (through libraries) or authors. But the prices charged by journals publishers to access these journals have increased dramatically, forcing many libraries to cancel subscriptions. In economic terms, these for-profit journals are a privately owned club good, and as the number of club-members decreases, the price per member increases to maintain the facility—a vicious cycle familiar to any analyst of transit ridership.

The model for JTLU differs from that described above in that we see scientific knowledge as a public good best provided without profit by public-minded institutions. The open-content movement is gaining ground throughout scientific literature. In biology, for example, the Public Library of Science (PLoS) has led the way in legitimizing this new model of distribution.

JTLU is open-content, subscription-free, and free to contribute. All of this is enabled by generous financial and administrative support from the Center for Transportation Studies at the University of Minnesota. The advantages of this new journal and new process are several:

1. With a rigorous peer-review process, only quality papers that meet scientific standards will be published within the journal.

2. By being web-based (and web-only), we reduce costs significantly compared with paper journals. Web-based publication allows a much faster turnaround time than paper publication. Our goal is six weeks between submission and first reviews returned to the author. Being web-based also allows the inclusion of full color graphics and multi-media content, and the inclusion of datasets with the publication.

3. By being open-content, papers published in JTLU can be freely distributed (with attribution), increasing the value of papers published in the journal, and increasing their likelihood of being used in course readers and being read by the public. 
All papers are published under a Creative Commons license.

4. By being subscription-free, we overcome a fundamental problem of today's expensive journals published by for-profit publishers, which many libraries can no longer afford.

5. By being free-to-contribute, we overcome the burden of the open-content journals that charge the authors to publish their paper.

If you are reading this, you probably already know this journal can be found at http://www.jtlu.org. This website will be where you access articles, and is also the interface for managing the review process (from submitting articles for consideration to peer review and to editorial publication).

To date you will see this issue comprises several published articles. At the time of the writing, prior to a single volume being published, we have received 44 submissions (some of them through multiple iterations) for both general issues and planned future special issues. The latter will focus on Implications of Land Use and Transport on the Mobility Impaired, Networks and Commuting, and Transport and Land Use in China. If you are interested in contributing, we strongly encourage you to consider submitting original, top-notch research to the Journal. We anticipate several issues per year, and intend to maintain a regular publication cycle.

JTLU will only succeed if it attracts and publishes first-rate articles. Those articles will present many perspectives from authors trained in many different (and perhaps multiple) disciplines. Such an interdisciplinary perspective requires an open mind on the part of both editors and readers, so that the inter-disciplinarity can blossom and ultimately cross-pollinate the many fields that have a stake in this discourse. Collectively we aim to drive the golden spike connecting the complementary domains of transport and land use. 